\title{
ESCALA DE PRODUÇÃO EM EMPRESAS DE TRANSPORTE POR ÔNIBUS A EXPERIENNCIA BRASILEIRA
}

\author{
Étienne Henry \\ Diretor de pesquisa do INRETS - Instituto Francês de \\ Pesquisa sobre Transportes e sua Segurança. Professor- \\ visitante da EAESP/FGV de 1991 à 1993. \\ E-mail: henry@inrets.fr
}

Uma primeira versão deste trabalho, Echelle d'explortation des entreprises de transport por autobus, foi apresentada na Conferência sobre o desenvo/vimento dos transportes urbanos, Codatu VII, New Delhi, 12 - 16/2/96

TRADUÇĀO: Enrique Torres.

RESUMO: As economias de escala representam uma importante e polêmica questão dentro do debate em torno dos meios de transporte urbanos. A proliferação de pequenas empresas (geralmente predominantes nos países em desenvolvimento) induz à fragmentação de redes e métodos operacionais. Sendo assim, as administrações municipais procuram empresas que possuam grande número de ônibus e que possam assumir de forma completa e coordenada todos os aspectos operacionais do serviço. Entretanto, o tamanho dessas empresas pode trazer dificuldades no que concerne à rentabilidade, às economias externas e à produtividade. Do ponto de vista teórico, existe oposição à questão das economias de escala, consideradas negativas no setor de transportes. Entretanto, a análise da experiência brasileira leva a outras conclusões. Cerca de 1.500 empresas de ônibus urbanos são, em sua maior parte, privadas, ultrapassando o pequeno porte: propomos aqui sua classificação em oito tipos de escala. Por conseguinte, estudaremos as características operacionais e estruturais de cada uma delas. Os dados empíricos provêm de uma pesquisa em que houve a cooperação entre o meio científico e aqueles que operam os meios de transporte no Brasil (empresas públicas ou privadas). Contudo, as conclusões não se limitam nem à experiência nacional brasileira, nem ao contexto das cidades em desenvolvimento. Teoricamente, lançam uma dúvida sobre a atual presunção de que inexistem economias de escala nas empresas de ônibus.

ABSTRACT: Scale savings is a main polemical matter in the debate on urban transport utilities. The proliferation of small production units, generally dominating in developing countries, induces split up networks and operation modes. So city managers can look for buses concentration and for firms which manage the service operation aspects in a complete and coordinated manner. But difficulties may arise from their size as far as commercial profitability, external savings and service productivity are concerned. From a theoretical point of view, one comes up against the question of scale savings in transport: it is supposed to be negative. The analysis of the Brazilian experience leads to other conclusions. About 1.500 urban bus transport firms are mostly private owned and overcome the small scale: it is here proposed their grading in 8 scale types. Hence, structural and operating characteristics of each type are studied. The empirical data result from a research held in cooperation with the scientific and public ou private operational representatives of urban transport in Brazil. But the conclusions are not limited neither to the national Brazilian experience, nor to the context of developing cities. In theory, they throw a doubt about the current presumition of a lack of economies of scales in bus companies.

PALAVRAS-CHAVE: economias de escala, transporte urbano, empresas de ônibus, eficiência produtiva.

KEY WORDS: scale savings, urban transport, bus companies, operational performance. 


\section{A QUESTÃO DAS ECONOMIAS DE ESCALA DA UNIDADE PRODUTIVA}

O tamanho ideal das operadoras dos serviços de transporte é questão recorrente do debate sobre a organização desses nas cidades em desenvolvimento. A unidade de produção dos serviços pode assumir o caráter de uma pequena ou grande empresa, pública ou privada, explorando serviços de ônibus ou microônibus e operando em uma rede metropolitana de forma mais ou menos centralizada ou diversificada. Entretanto, as formas mais usuais de participação da iniciativa privada baseiam-se na pequena propriedade, que presumivelmente produz serviços mais adequados e a menor custo. A discussão sobre esse ponto merece ainda aprofundamento maior, pois a proliferação de pequenas unidades de produção do serviço poderá induzir à fragmentação das redes e de seus recursos para a operação. A posse de grande número de ônibus é um pré-requisito à constituição de empresas, as quais assumem de forma completa, autônoma e coordenada, todos os aspectos ligados à operação do serviço. Mas, quanto ao seu tamanho, levantam-se questões sobre a rentabilidade comercial, as economias externas e a produtividade do serviço. Sem considerar todas as modalidades de prestação dos serviços de transporte rodoviário urbano, este trabalho objetiva esclarecer os problemas referentes às empresas de ônibus, excluindo os outros tipos de unidades e veículos.

Do ponto de vista teórico, a análise reduzir-se-ia à questão das economias de escala nos transportes. A análise clássica da questão, feita por meio da função de custos, faz com que os desempenhos relativos, medidos em veículos/quilômetro ou em passageiros/quilômetro produzidos dependam da estrutura de preços dos fatores de produção e das variáveis externas, como o tamanho das cidades ou a velocidade comercial dos ônibus. Sendo o custo médio a relação entre o custo total e a quantidade produzida e sendo o custo marginal igual ao custo de produção de uma unidade suplementar, as economias de escala tornam-se decrescentes quando o custo médio de longo prazo é superior ao custo marginal, e crescentes, na situação inversa.

Sem jamais reconhecer a presença de economias de escala positivas no setor de transportes urbanos, as diferentes gerações de modelos, produzidos com base em séries cronológicas ou comparativas, indicam, nos países industrializados, rendimentos estáveis ou decrescentes com o aumento do tamanho das empresas. Os modelos não apresentam, entretanto, explicações concretas, e imputam à grande participação dos custos salariais a diferença entre os transportes e os setores industriais onde se manifestam economias de escala.

A experiência internacional parece mostrar que dificilmente o custo marginal pode ser inferior ao custo médio quando o acréscimo de um veículo à operação implica custos de mãode-obra sem relação com o aumento do serviço obtido. Tais preceitos seriam válidos nas cidades dos países em desenvolvimento? As relações entre os custos de mão-de-obra e o custo dos veículos nessas cidades são sensivelmente diferentes, os últimos contando mais que os primeiros em certas funções de produção. Por outro lado, as exigências de qualidade dos serviços diferem notavelmente em comparação com o contexto urbano dos países industrializados, assim como as funções econômicas e sociais dos transportes e a intervenção regulamentadora do poder público. Ainda sem dispor de dados numéricos necessários à verificação de tal afirmação, pode-se observar o comportamento das variáveis internas à empresa, que influem no custo de produção. Se forem consideradas as características de escala de operação das empresas, haverá condição de se examinarem as divergências e convergências com a teoria em questão.

A experiência brasileira, com cerca de mil e quinhentas empresas, na maioria privadas, operando em todo o país nos mercados de transporte urbano e suburbano, permite, com efeito, que se estabeleça uma tipologia, de acordo com o tamanho das empresas e observando-se suas características. Esse universo, suficientemente diversificado entre grandes, médias e pequenas empresas, autoriza que se coloque o problema da escala de produção dos serviços.

Os dados empíricos provêm de uma pesquisa (associando o Inrets, a Orstom, a Fundação Getúlio Vargas e diversas universidades brasileiras) realizada em cooperação com o meio científico e os que operam o transporte urbano no Brasil. Primeiramente foi necessário proceder a uma observação sistemática das empresas presentes nos serviços de transporte urbano (e que agregam mais de cem mil ônibus) em cerca de 450 cidades, a fim de produzir uma primeira base de dados: OnibusLis, ou lista de ônibus urbanos por cidade, tamanho, estatuto e tipo de serviço. Em seguida, realizou-se uma pesquisa por correspondência, co- 
brindo mais de $10 \%$ do universo, que forneceu os dados gerais sobre a estrutura e as características dessas empresas em 1992, ainda que o método e a conjuntura inflacionária brasileira não permitissem estudar os aspectos de custo: OnibuCad, ou cadastro das empresas de transporte urbano por ônibus. Enfim, uma série de abordagens qualitativas nas empresas e junto às entidades profissionais e órgãos de gerência forneceram os elementos para uma interpretação desses dados (pesquisa Orstom/ CNPq, Trajetória e perspectivas de uma profissionalidade urbana: o universo das empresas brasileiras de ônibus).

Aqui, a atenção concentra-se no tratamento dos dados fornecidos pela pesquisa OnibuCad. A partir dela, pôde-se obter uma tipologia das empresas segundo o tamanho e analisar o valor explicativo de suas dimensões e nível de equipamento, do gerenciamento e modernização, de sua produtividade física e operacional, a fim de explicar o crescimento e a concentração das empresas privadas de ônibus.

Os ensinamentos que se podem tirar dessa referência ultrapassam os limites da experiência brasileira. Eles podem ao menos ser relacionados a situações similares tomando em conta as especificidades brasileiras que provêm da dimensão do mercado nacional dos transportes urbanos. Mas podem também fornecer elementos de resposta ao debate sobre as escalas de produção e as formas de empresas adequadas ao contexto dos países em desenvolvimento.

\section{TIPOLOGIA DAS EMPRESAS BRASILEIRAS DE ÔNIBUS}

O transporte coletivo urbano comporta inúmeras facetas, segundo a dinâmica dos mercados e a organização do gerenciamento, cujas práticas regulamentadoras diferem entre si. A mais evidente é a do transporte municipal, estruturado em uma mesma cidade e regido por um órgão de gerência. No atendimento às periferias urbanas operam empresas intermunicipais, sob a tutela do estado ou de uma instância metropolitana. $O$ transporte regional conecta certos núcleos urbanos entre si, encontra-se sob tutela do governo do Estado (ou da União quando se trata de linhas interestaduais). A essas formas institucionalizadas do transporte somam-se outras, notadamente as do fretamento, que tanto podem se referir a zonas industriais ou administrações particulares, quanto a grupos específicos da deman- da social por transporte. As empresas exploram esses diferentes mercados, geralmente, de forma especializada, pois certos órgãos de gerência exigem uma exclusividade para o serviço, mas, às vezes, também de forma combinada - uma mesma empresa opta por diversificar sua oferta ao participar dos mercados municipais e intermunicipais. Da mesma forma, pequenos transportadores passam pelos transportes especiais antes de atingir o tamanho crítico que lhes permita ascender ao serviço municipal; ou o serviço municipal pode ser menos importante que o fretamento no caso de aglomerações em pleno crescimento. Portanto, no contexto do processo de urbanização ainda em curso, deve-se considerar como transporte urbano essas diferentes facetas do serviço, em relação às quais as empresas estruturam-se.

Uma tipologia pode partir do tamanho das empresas, o que permite analisar seu processo de constituição. Entretanto, as estruturas das unidades de produção do serviço não variam apenas segundo o tamanho das empresas, o qual expressa grosseiramente as diferentes maneiras de organizar os fatores de produção. Essas maneiras estão relacionadas tanto com o mercado explorado, segundo os tipos de cidades, de clientelas e de serviços prestados, quanto com o gerenciamento interno das unidades de produção. Por outro lado, o critério "tamanho das empresas" deve ser especificado: tanto é possível relacioná-lo à quantidade de veículos quanto às instalações fixas, ao pessoal empregado ou aos mercados explorados.

Em função dessas considerações, essa tipologia parte de um critério referido essencialmente ao tamanho das unidades de produção, exigindo que se encontre por aí a sua lógica própria e a sua tendência a se estabilizar ou a evoluir para um tipo mais desenvolvido de empresa. O nível mais baixo corresponde a "um único veículo com seu motorista", o qual é geralmente também o seu proprietário. Em seguida, as unidades de produção individual tendem a transformarem-se em microempresas, operando diversos ônibus e com pessoal assalariado. No outro extremo, as maiores empresas (localizadas em São Paulo, Rio de Janeiro e Brasília) são líderes de grupos que concentram uma, ou mesmo várias, dezenas de empresas que operam em uma ou várias cidades. Encontram-se também grupos nacionais constituídos por empresas de menor tamanho, que adotam as mesmas práticas monopolistas nos mercados locais. Além disso, a diferença regional é marcante: o que se considera uma
A experiência brasileira, com cerca de mile quinhentas empresas, na maioria privadas, operando em todo o país nos mercados de transporte urbano $e$ suburbano, permite, com efeito, que se estabeleça uma tipologia de acordo com o tamanho das empresase observando-se suas características. 
grande empresa no Nordeste seria antes visto no Sul como uma empresa média.

A figura 1 e a tabela 1 ilustram o grau de concentração do transporte urbano, fator dominante no Brasil. Os quatro primeiros tipos reúnem mais de $40 \%$ dessas empresas e absorvem $80 \%$ da frota nacional. São as empresas cujas frotas ultrapassam 75 ônibus, mas que podem atingir 10 vezes esse valor. E deve-se notar que cerca de dois terços dos veículos estão concentrados em um quinto das empresas.

TABELA 1

\begin{tabular}{|c|c|c|c|}
\hline \multicolumn{4}{|c|}{$\begin{array}{c}\text { Distribuição das empresas } \\
\text { brasileiras de ónibus urbanos }\end{array}$} \\
\hline Tipo & Frota & Empresas & Ónibus \\
\hline A & acima de 350 & $3 \%$ & $20 \%$ \\
\hline B & $200-349$ & $10 \%$ & $42 \%$ \\
\hline C & $135-199$ & $21 \%$ & $60 \%$ \\
\hline D & $76-134$ & $38 \%$ & $80 \%$ \\
\hline E & $46-75$ & $52 \%$ & $90 \%$ \\
\hline F & $20-45$ & $73 \%$ & $97 \%$ \\
\hline G & $11-19$ & $85 \%$ & $99 \%$ \\
\hline H & até 10 & $100 \%$ & $100 \%$ \\
\hline
\end{tabular}

FIGURA 1

Fonte: OnibuLis

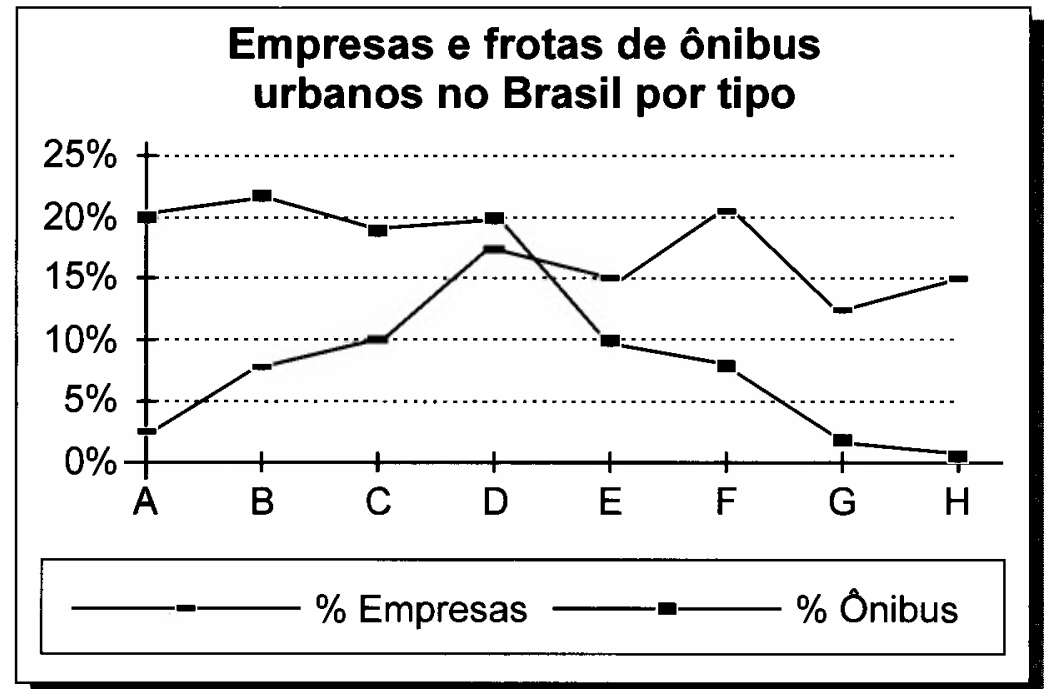

Fonte: OnibuLis

A dispersão é muito maior nos quatro tipos inferiores, que concentram mais da metade das empresas mas apenas $20 \%$ da frota nacional de ônibus urbanos. Assim, pode se dizer que a grande empresa domina o panorama do transporte urbano brasileiro do ponto de vista da capacidade oferecida, enquanto as pequenas em- presas são ainda preponderantes do ponto de vista das unidades de produção do serviço. Longe de poder-se opor um setor moderno a um setor tradicional, observam-se diferentes tipos de empresas cujas características variam tanto do ponto de vista dos mercados quanto de seu funcionamento interno.

- O tipo A, que se poderia chamar de megaempresa, cuja frota é superior a 350 ônibus, é fortemente marcado pelas tendências monopolistas dos grandes grupos que tentam impor-se em escala nacional. Pouco numerosas, essas empresas concentram, entretanto, um quinto da frota nacional de ônibus urbanos.

- As empresas de tipo B, entre 200 e 350 veículos, representam apenas cerca de $7 \%$ do total, mas formam a categoria mais numerosa em termos de frota. São essencialmente grandes empresas que dominam os mercados metropolitanos de transporte urbano.

- As empresas do tipo $C$ são também de tamanho respeitável (entre 135 e 200 veículos) e operam nas regiões metropolitanas, combinando freqüentemente serviços municipais $\mathrm{e}$ intermunicipais.

- O tipo D, entre 75 e 135 ônibus, $\mathrm{re}_{\boldsymbol{\mu}}$ esenta as empresas em crescimento. Elas são relativamente numerosas, já que representam $17 \%$ do universo.

- As empresas do tipo E, entre 45 e 75 ônibus, são tipicamente de médio porte. Embora sua importância numérica seja grande (14\%), não representam mais de $10 \%$ da frota total. São encontradas, sobretudo, nas capitais e cidades médias.

- O tipo $\mathrm{F}$ compreende $21 \%$ das empresas brasileiras, sua frota oscila entre 20 e 45 ônibus, e corresponde a $7 \%$ da frota nacional; elas estão presentes sobretudo nas cidades médias. - As empresas do tipo G, entre 11 e 20 veículos são geralmente pequenas empresas familiares; com cerca de $12 \%$ do total das empresas brasileiras, correspondem a $2 \%$ da frota nacional de ônibus.

- As empresas do tipo H, na faixa de até uma dezena de ônibus, representam cerca de $15 \%$ do número total das empresas brasileiras de transporte urbano, mas reúnem menos de $1 \%$ da frota nacional. A maior parte dedica-se essencialmente aos serviços de transporte fretado.

\section{DIMENSÕES DAS EMPRESAS}

Informações mais detalhadas, obtidas por meio de amostragens, permitem análises mais 
TABELA 2

\begin{tabular}{|c|c|c|c|}
\hline \multicolumn{4}{|c|}{ Amostra das empresas } \\
\hline Tipo & Frota média & Empresas & Ônibus \\
\hline A & 498 & $4,07 \%$ & $17,01 \%$ \\
\hline B & 268 & $14,63 \%$ & $32,98 \%$ \\
\hline C & 162 & $13,82 \%$ & $18,83 \%$ \\
\hline D & 93 & $22,76 \%$ & $17,78 \%$ \\
\hline E & 61 & $19,76 \%$ & $4,98 \%$ \\
\hline F & 34 & $26,02 \%$ & $7,54 \%$ \\
\hline G & 14 & $6,50 \%$ & $0,78 \%$ \\
\hline H & 5 & $2,44 \%$ & $0,10 \%$ \\
\hline Total & 119 & $100 \%$ & $100 \%$ \\
\hline
\end{tabular}

Fonte: OnibuCad

profundas. Uma primeira leitura dos dados já mostra grande heterogeneidade e assinala tendências à concentração nos quatro primeiros tipos de empresa, havendo ainda, no entanto, alguma dispersão nas categorias das pequenas empresas.

Na tabela 2, a frota média de 120 ônibus por empresa oculta, todavia, um grau muito elevado de dispersão, variando de 5 ônibus por empresa para o tipo $\mathrm{H}$ a 500 para o tipo A. Se o valor mediano situa-se em 80 ônibus, $85 \%$ da frota correspondem a empresas com mais de uma centena de veículos. Observa-se também, na tabela 3 que o tamanho das empresas varia conforme a idade: aquelas que ultrapassam o patamar de 200 ônibus têm mais de quarenta anos. As empresas médias (tipo E) são da ordem de 25 anos de existência, e as menores estão frequientemente em crescimento. A idade média dos ônibus (inferior no caso de empresas médias), jamais atinge os sete anos, salvo nos casos das pequenas empresas, (tipo $\mathrm{H}$ ) em que a idade média dos veículos é duas vezes mais elevada que nas grandes empresas. Existem diferentes estratégias de investimento com, num extremo, grandes empresas públicas que encontram dificuldades para renovar sua frota e, no outro, grandes empresários que preferem reduzir seus gastos em manutenção e aproveitar os benefícios da revenda de ônibus (assim, a idade média da frota no Rio de Janeiro é de apenas dois anos e meio).

O conceito de tamanho das empresas concerne também aos terrenos e edificações que possuem. Em valor absoluto, varia também

$R A E$ - v. 37 - n. 1 - Jan./Mar. 1997
TABELA 3

\begin{tabular}{|c|c|c|}
\hline \multicolumn{3}{|c|}{ Idade média das empresas e frotas } \\
\hline Tipo & Empresas & Ốnibus \\
\hline A & 42 & 5,60 \\
\hdashline B & 43 & 6,73 \\
\hline C & 30 & 6,20 \\
\hdashline D & 24 & 4,62 \\
\hline E & 26 & 4,67 \\
\hline F & 20 & 4,96 \\
\hline G & 15 & 6,57 \\
\hline H & 7 & 10,50 \\
\hline Total & 27 & 5,66 \\
\hline
\end{tabular}

Fonte: OnibuCad

conforme o tipo de empresa. Observa-se, entretanto, (tabela 4, terceira coluna), que a área dos terrenos relacionada à frota de ônibus varia inversamente com o tamanho das empresas. $\mathrm{O}$ investimento fundiário, portanto, não se compara à frota em operação, seja porque constitui um capital em si (assim, em 10\% das empresas a garagem é alugada a um proprietário diferente, que pode ser o sócio principal da empresa), seja em perspectiva de extensão da escala de operação (o que parece particularmente claro no caso das empresas do tipo G). Vê-se, portanto, melhor utilização do terreno pelas grandes empresas. As variações relacionadas à área construída são da mesma ordem. Quanto à área de estacionamento prevista para os ônibus, observa-se novamente (última coluna) um superdimensionamento variando em função inversa ao tamanho das empresas. Assim, pode-se dizer que o investimento fundiário é proporcionalmente superior no caso das pequenas e médias empresas e o investimento em veículos é mais elevado nas grandes empresas.

A dimensão das empresas, medida em termos de frota e terrenos, deveria determinar a dotação em equipamentos. Relacionada ao número de ônibus, essa regra, todavia, não é tão evidente quando se classificam as empresas segundo o número dos postos de manutenção nas oficinas, das bombas de combustível e dos veículos de socorro.

Nota-se, primeiramente, que o número médio de ônibus por valeta cresce do tipo $\mathrm{A}$ ao tipo $C$, o que em parte deve-se ao fato de que, nas empresas maiores, o número de valetas es-
O transporte coletivo urbano comporta inúmeras facetas, segundo a dinâmica dos mercados e a organização do gerenciamento, cujas práticas regulamentares diferem entre si. 
TABELA 4

Garagens, terrenos e prédios das empresas

\begin{tabular}{|c|c|c|c|c|c|c|}
\hline $\begin{array}{c}\text { Tipo } \\
\text { de } \\
\text { Empresa }\end{array}$ & $\begin{array}{c}\mathbf{N}^{\circ} \\
\text { de } \\
\text { Garagens }\end{array}$ & $\begin{array}{c}\text { Terrenos } \\
\mathbf{m}^{2}\end{array}$ & $\begin{array}{c}\text { Áreal } \\
\text { Ônibus } \\
\mathbf{m}^{2}\end{array}$ & $\begin{array}{c}\text { Área } \\
\text { Constr } \\
\mathbf{m}^{2}\end{array}$ & $\begin{array}{c}\mathbf{N}^{\circ} \\
\text { de } \\
\text { Vagas }\end{array}$ & $\begin{array}{c}\text { (valores } \\
\text { médios) } \\
\text { Vagas/Frota }\end{array}$ \\
\hline A & 1,80 & 57969 & 119 & 13474 & 513 & $3 \%$ \\
\hline B & 2,00 & 39028 & 148 & 10296 & 304 & $12 \%$ \\
\hline C & 1,56 & 16865 & 104 & 4295 & 196 & $17 \%$ \\
\hline D & 1,27 & 10046 & 140 & 2798 & 111 & $16 \%$ \\
\hline E & 1,17 & 12230 & 238 & 1674 & 132 & $54 \%$ \\
\hline F & 1,03 & 9297 & 274 & 1430 & 60 & $43 \%$ \\
\hline G & 1,13 & 11394 & 708 & 2598 & 42 & $66 \%$ \\
\hline H & 1,00 & 1800 & 290 & 483 & 18 & $71 \%$ \\
\hline Total & 1,36 & 18374 & 244 & 4067 & 153 & $22 \%$ \\
\hline
\end{tabular}

Fonte: OnibuCad

pecializadas por tipo de veículo e por tarefa de manutenção aumenta. $\mathrm{O}$ aumento do tamanho da empresa tem por efeito diversificar e multiplicar as tarefas de manutenção (preventiva). A partir de certo tamanho crítico, tornase preferível proceder a um número crescente de atividades de manutenção no interior da empresa a fazê-lo fora dela. É o que acontece com a pintura e a manutenção pesada da mecânica e da carroceria. $\mathrm{O}$ número de bombas de combustível diminui regularmente segundo o tamanho da empresa, o que permite depreender uma subutilização desse equipamento e dos estoques de combustível entre as empresas me-

FIGURA 2

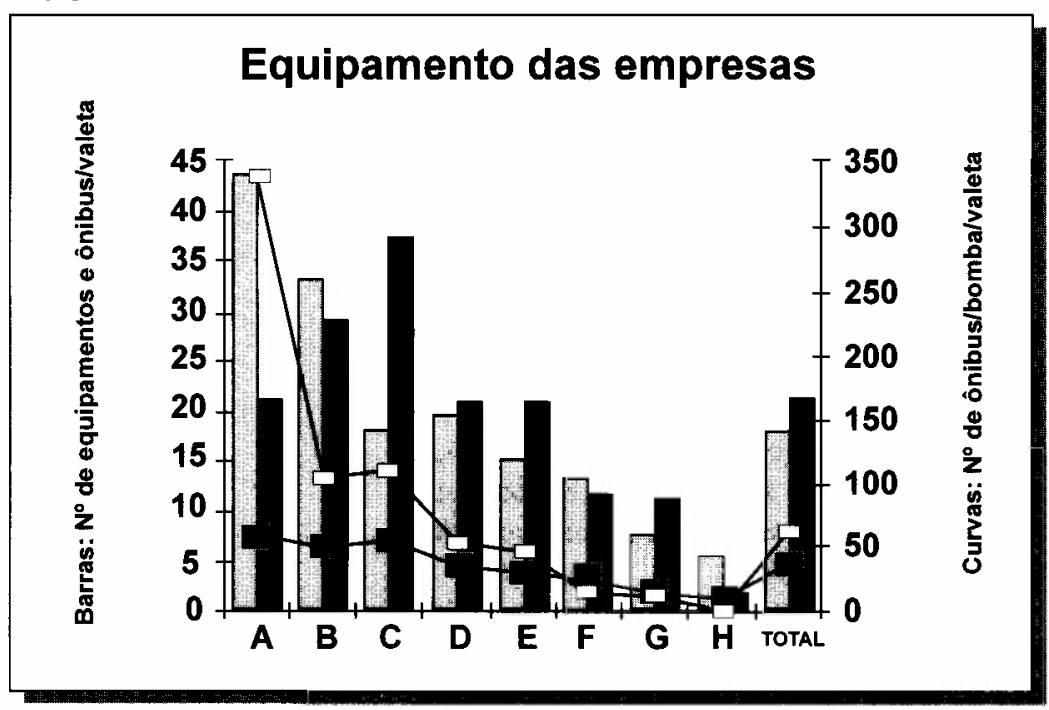

Fonte: OnibuCad

nores. Finalmente, o número de ônibus por veículo de socorro também diminui, de maneira muito mais acentuada. Um adepto da teoria das economias de escala poderia ver aqui um fator de aumento dos custos de produção. Supondo-se, no entanto, idêntica qualidade de serviço, parece que os equipamentos e infraestruturas de manutenção são ao mesmo tempo mais numerosos e mais bem aproveitados nas grandes do que nas pequenas empresas.

\section{ESCALA E GESTÃO DAS EMPRESAS}

O gerenciamento das empresas responde grosso modo a dois princípios de organização: aquele em que domina o espírito de organização familiar e, por oposição, o que é determinado por uma lógica mais profissional. No primeiro caso, que se pode qualificar de "gerenciamento familiar", a empresa é marcada pelas relações primárias entre os detentores do patrimônio e a organização da atividade. $\mathrm{O}$ bom senso prevalece sobre os conhecimentos técnicos e um certo paternalismo sobre uma organizaçãc :acional do trabalho. No "gerenciamento empresarial", busca-se atingir os objetivos de operação, manutenção e qualidade do serviço. Colocam-se em prática mecanismos de controle e programação da operação em função da demanda. Definem-se políticas de investimento, em material rodante e instalações fixas, em função dos planos da empresa.

Empiricamente, pode-se qualificar o gerenciamento das empresas em função de quatro critérios :

- a organização, aqui relacionada ao controle da operação, à programação operacional e à existência de um organograma;

- a modernização, aqui avaliada pela utilização da informática para as atividades de contabilidade, operação, abastecimento, manutenção e outras;

- a manutenção, medida pelo número de atividades internalizadas na empresa, dentre uma gama de dez que vão da pintura ( $90 \%$ das empresas) à recuperação dos veículos $(77 \%)$, dos pneus $(25 \%)$ e até à fabricação de peças (13\%); - a política social praticada em relação ao pessoal, em matéria de saúde ( $62 \%$ das empresas), de formação (48\%), de alimentação dos trabalhadores $(39 \%)$, recreação $(38 \%)$ e alojamento no local (21\%).

Cada um desses critérios é aqui ponderado em relação à frequiência de sua ocorrência nas empresas, o que nos fornece indicadores 
para cada rubrica, que se podem agrupar num índice de conjunto, mostrados na tabela 5 , abaixo. caso, mais que de uma subcontratação externa, trata-se realmente, de uma preocupação menor com esse aspecto da empresa.

TABELA 5

\begin{tabular}{|c|c|c|c|c|c|}
\hline \multicolumn{7}{|c|}{ Indicadores de gerenciamento das empresas } \\
\hline Tipo & Organização & Informática & Manutenção & Pessoal & Total \\
\hline A & 2,40 & 3,67 & 5,20 & 2,67 & 13,93 \\
\hline B & 2,13 & 3,58 & 5,39 & 2,25 & 13,36 \\
\hline C & 1,50 & 3,36 & 5,94 & 2,09 & 12,90 \\
\hline D & 1,56 & 3,59 & 6,00 & 2,65 & 13,79 \\
\hline E & 0,08 & 1,67 & 5,42 & 1,67 & 8,83 \\
\hline F & 1,11 & 2,70 & 5,38 & 1,40 & 10,58 \\
\hline G & 0,86 & 1,71 & 3,00 & 2,14 & 7,71 \\
\hline H & 1,67 & 2,00 & 3,67 & 1,50 & 8,83 \\
\hline Total & 1,35 & 3,03 & 5,40 & 2,05 & 11,83 \\
\hline
\end{tabular}

Fonte: OnibuCad

O valor dos indicadores de organização dos quatro primeiros tipos de empresa é superior à média, o que confirma a idéia de que o gerenciamento é mais racionalizado nas grandes empresas. Por outro lado, ainda que de modo aleatório, é inferior nas empresas de menor tamanho. Para a modernização das empresas segundo o seu recurso à informática (presente em mais de $85 \%$ das empresas brasileiras), mais da metade ( $62 \%$ das empresas) utiliza-a em pelo menos três atividades, o que mostra o alto grau de difusão dessas técnicas; e perto de um quarto das empresas utilizamna para duas atividades. Segundo esse critério, as empresas mais modernas seriam as maiores e os quatro primeiros tipos situam-se acima de um valor médio de um pouco mais de três formas de utilização, enquanto os quatro últimos tipos de empresa ficam abaixo desse valor.

A capacidade de manutenção, medida por um indicador que compatibiliza a diversidade de atividades realizadas no interior da empresa, não varia diretamente segundo o seu tamanho. Parece que a manutenção estaria melhor assegurada, ou internalizada, entre as empresas de tamanho médio ou em evolução. As maiores empresas, por seu tamanho e antigüidade, realizam atividades de manutenção menos diversificadas. $\mathrm{Na}$ base da escala, encontramse as pequenas empresas, que possuem uma menor variação de atividades de manutenção: nesse
Enfim, o número médio de benefícios sociais oferecidos pela empresa varia segundo o seu tamanho. Novamente, os tipos A a D encontram-se acima da média, provavelmente por causa das dinâmicas conjuntas das empresas e dos sindicatos de trabalhadores. Os diferentes indicadores ilustram ainda a confrontação entre os dois modos de gerenciamento, o familiar e o empresarial. O primeiro atribui grande importância ao pragmatismo, enquanto o segundo baseia-se preferencialmente nas relações despersonalizadas e visa a desenvolver as atividades contínuas de operação e manutenção. A diferenciação entre esses dois modos passa pelo tamanho da empresa, como o mostra o índice de conjunto que cresce correlativamente à tipologia. Resta saber qual é o mais favorável à economia de escala.

\section{ESCALA E PRODUTIVIDADE DAS EMPRESAS}

O aumento de escala da empresa deve permitir aumentar a produtividade, sobretudo se estiver acompanhado de modernização e aprimoramento técnico das instalações, dos veículos e da empresa. Entretanto, geralmente se afirma que nenhuma lei de rendimentos crescentes é aplicável ao transporte urbano. Sem dispor de dados comerciais, pode-se considerar um certo número de indicadores físicos de operação que exprimam indiretamente a produtividade. 
Sob o ângulo da produtividade do trabalho, observam-se diferenças significativas entre os oito tipos de empresas de transporte urbano no Brasil (tabela 6). O quadro de pessoal varia de apenas 1 até 3.775 empregados, com estabelecimento do valor médio de 582 por empresa. Assim, o efetivo médio por tipo de empresa diminui regularmente de 2639 , para o tipo A, até 7 , para o tipo $\mathrm{H}$, a variação é muito grande. A organização da produção das empresas que ultrapassam mil empregados (nos tipos A e B) não segue os mesmos critérios das que não atingem a uma centena como é o caso dos tipos G e H. Entre essas grandes e pequenas empresas, existem vários patamares que separam umas das outras, conforme seus efetivos ultrapassem os 100 ou 500 empregados.

\section{TABELA 6}

\begin{tabular}{|c|c|c|}
\hline \multicolumn{3}{|c|}{ Pessoal das empresas } \\
\hline Tipo & $\begin{array}{c}\text { Número } \\
\text { Médio }\end{array}$ & $\begin{array}{c}\text { PessoasI } \\
\text { Ônibus }\end{array}$ \\
\hline A & 2639 & 5,27 \\
\hline B & 1383 & 5,19 \\
\hdashline C & 790 & 4,8 \\
\hline D & 403 & 4,11 \\
\hline E & 255 & 3,95 \\
\hline F & 120 & 3,62 \\
\hline G & 48 & 3,05 \\
\hline H & 7 & 0,98 \\
\hline Total & 582 & 4,14 \\
\hline
\end{tabular}

Fonte: OnibuCad

Quando medida pela simples razão entre o efetivo e a frota empresarial, a produtividade do trabalho decresce regularmente com o aumento do tamanho da empresa. Ocorreria, portanto, um efeito inverso de escala, as maiores empresas sendo maiores consumidoras de mãode-obra. Quais seriam, então, os patamares sociais que provocariam custos excessivos de gerenciamento de pessoal?

Em oposição às economias de escala, invoca-se a importância fundamental dos custos de mão-de-obra na produção dos serviços de transporte, que causariam custos salariais relativamente crescentes. No caso brasileiro, a amortização dos veículos e a aquisição de peças de reposição guardam no entanto uma notória importância, amplamente superior a que se observa nos países industrializados. Sendo assim, quais as categorias de pessoal mais significativas (tabela 7)? Primeiramente, o pessoal de operação, que varia segundo o mesmo ritmo dos efetivos totais por empresa: as menores têm menos de um motorista por ônibus, mas, se por um lado, o serviço de fretamento usual nessas pequenas empresas permite que se economize o custo do cobrador, por outro lado, a frota é subutilizada, com um número apreciável de veículos de reserva devido à organização do serviço e ao estado dos ônibus. Para os outros tipos de empresa, a quota mais baixa são dois empregados, um motorista e um cobrador, por veículo (norma comumente imposta pelo órgão gerenciador, salvo exceções, em que o último é substituído pela bilhetagem automática, ainda pouco adotada no Brasil). Entre as pequenas e grandes empresas de transporte municipal, a regra é o dobro, atingindo, no tipo A, 4,23 motoristas e cobradores por ônibus. Nas grandes empresas, a adoção generalizada de três turnos de serviço faz aumentar essas categorias de pessoal. Nas pequenas e médias, faz-se maior uso de hora extra. Como regra geral, a produtividade do pessoal de operação diminui com o tamanho das empresas.

\section{TABELA 7}

\begin{tabular}{|c|c|c|c|}
\hline \multicolumn{3}{|c|}{ Categorias de pessoal (pessoas/ônibus) } \\
\hline Tipo & Operação & $\begin{array}{c}\text { Manu- } \\
\text { tenção }\end{array}$ & $\begin{array}{c}\text { Adminis- } \\
\text { tração }\end{array}$ \\
\hline A & 4,23 & 0,58 & 0,23 \\
\hdashline B & 4,06 & 0,55 & 0,34 \\
\hdashline C & 3,60 & 0,42 & 0,28 \\
\hdashline D & 3,17 & 0,40 & 0,35 \\
\hline E & 3,11 & 0,29 & 0,43 \\
\hline F & 2,75 & 0,25 & 0,31 \\
\hline G & 2,07 & 0,20 & 0,30 \\
\hdashline H & 0,70 & 0,04 & 0,24 \\
\hline Total & 3,16 & 0,36 & 0,33 \\
\hline
\end{tabular}

Fonte: OnibuCad

Ocorre o mesmo tipo de variação no que se refere ao pessoal de manutenção. Mas não se pode atribui-la à norma regulamentar ditada pelo órgão de gerência. Trata-se, nesse caso, da característica (inerente a todos os tipos de empresa) de empregar mais ou menos mecâ- 
nicos para a manutenção dos veículos. E a variação é extremamente importante, pois, das pequenas às maiores empresas, passa-se de 4 a 58 mecânicos por 100 ônibus. Não apenas a qualidade do serviço está em causa (manutenção preventiva, por exemplo), mas também a política de manutenção das frotas, muito mais desenvolvida nas maiores empresas. Finalmente, postula-se que o aumento de tamanho da empresa propicia aumento considerável de pessoal administrativo. Essa hipótese não se verifica aqui, pois a variação do número de empregados administrativos e de gerentes proporcionalmente ao número de veículos é aleatória (tem-se aproximadamente a mesma relação nas pequenas e nas grandes empresas). da segundo critérios físicos de operação, mais especificamente, em relação ao número de passageiros transportados por mês e à quilometragem percorrida pelos veículos, usualmente conhecida por IPK. Tal produtividade varia fortemente segundo o tipo de serviço de transporte urbano prestado pelas empresas. Obtémse, então, uma produtividade da ordem de três passageiros por quilômetro percorrido, nos serviços municipais. Esse valor cai a quase metade $(1,73)$ no transporte urbano intermunicipal, que concerne essencialmente às ligações centro-subúrbio e aos atendimentos às periferias, o que é natural: as distâncias percorridas são maiores. Isso não impede que a produtividade financeira desse tipo de serviço, menos con-

\section{FIGURA 3}

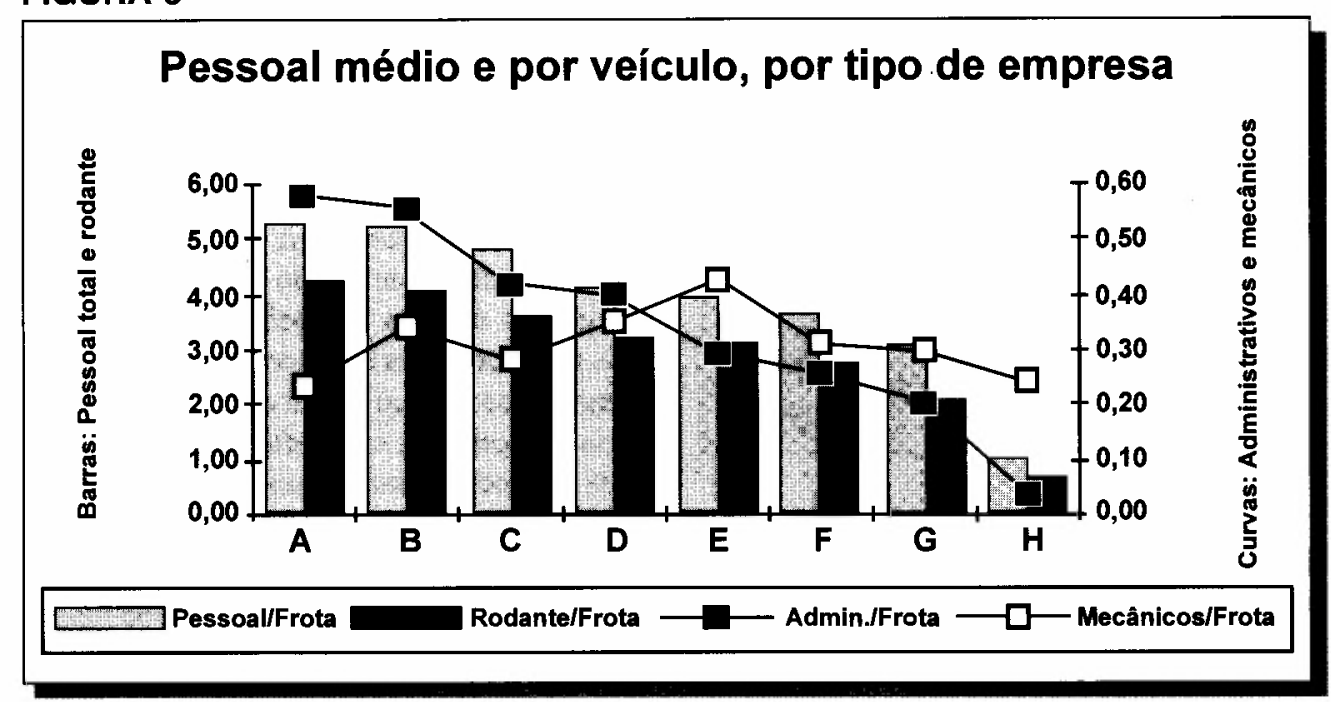

Fonte: OnibuCad

A figura 3 parece indicar que a produtividade global do trabalho decresce à medida que cresce o tamanho das empresas, embora deva ser discriminada segundo as diferentes categorias de pessoal. Seria necessário, entretanto, colocar em questão a qualidade do serviço (que não é necessariamente equivalente entre os diversos tipos de empresa) e as políticas de gerenciamento, podendo ser atribuída maior ou menor importância ao pessoal do que à frota. Assim, nas maiores, o gerenciamento da frota teria maior importância que o de pessoal, o que parece ter uma relação direta com o tipo de gerenciamento: na familiar, a preocupação maior é economizar mão-de-obra, enquanto na de gerenciamento empresarial, enfatiza-se a aquisição e a manutenção dos ônibus.

A produtividade deve também ser avalia- trolado pelo poder concedente, seja rentável. Note-se que parte considerável das empresas realiza esse serviço conjuntamente com o poder municipal. Em seguida, a produtividade operacional cai para os serviços de transporte urbano ligados a atendimentos regionais ou interurbanos. Por outro lado, ela sobe novamente se considerarmos o transporte não regulamentado, como o fretamento urbano, que apresenta 1,33 passageiros por quilômetro. Tais variações são significativas, embora não tenham uma relação direta com a rentabilidade comercial. Nas tabelas a seguir, será dada, portanto, atenção apenas ao serviço de transporte municipal (exceção feita ao tipo $\mathrm{H}$ para o qual se guardam os valores do transporte fretado).

Pode-se observar, na figura 4, que o número de passageiros transportados por ônibus cresce do tipo A ao tipo E, o que indica que os ôni-
As

comparações entre cidades $e$ países, entre empresas ou entre linhas de uma mesma rede, obrigam a que se saía do estrito quadro da economia marginalista. 
bus das empresas maiores transportam normalmente menos passageiros que os das médias, em prejuízo, portanto, do rendimento comercial das primeiras. Embora de maneira mais acidentada, a capacidade oferecida, medida em termos de quilômetros/ônibus médios, varia no mesmo sentido. Pode-se deduzir daí que, além de cinquienta ônibus por empresa (tipo F), ma-

FIGURA 4

\begin{tabular}{|c|c|c|c|c|c|c|}
\hline \multicolumn{7}{|c|}{ Garagens, terrenos e prédios das empresas } \\
\hline $\begin{array}{c}\text { Tipo } \\
\text { de } \\
\text { Empresa }\end{array}$ & $\begin{array}{c}\text { No } \\
\text { de } \\
\text { Garagens }\end{array}$ & $\begin{array}{c}\text { Terrenos } \\
\text { m }^{2}\end{array}$ & $\begin{array}{c}\text { Áreal } \\
\text { Ónibus } \\
\text { m }^{2}\end{array}$ & $\begin{array}{c}\text { Área } \\
\text { Constr. } \\
\text { m }^{2}\end{array}$ & $\begin{array}{c}\mathbf{N}^{\circ} \\
\text { de } \\
\text { Vagas }\end{array}$ & $\begin{array}{c}\text { (valores } \\
\text { médios) } \\
\text { Vagas/Frota }\end{array}$ \\
\hline A & 1,80 & 57969 & 119 & 13474 & 513 & $3 \%$ \\
\hline B & 2,00 & 39028 & 148 & 10296 & 304 & $12 \%$ \\
\hline C & 1,56 & 16865 & 104 & 4295 & 196 & $17 \%$ \\
\hline D & 1,27 & 10046 & 140 & 2798 & 111 & $16 \%$ \\
\hline E & 1,17 & 12230 & 238 & 1674 & 132 & $54 \%$ \\
\hline F & 1,03 & 9297 & 274 & 1430 & 60 & $43 \%$ \\
\hline G & 1,13 & 11394 & 708 & 2598 & 42 & $66 \%$ \\
\hline H & 1,00 & 1800 & 290 & 483 & 18 & $71 \%$ \\
\hline Total & 1,36 & 18374 & 244 & 4067 & 153 & $22 \%$ \\
\hline
\end{tabular}

Fonte: OnibuCad tudo, não é significativa e dificilmente poderse-ia deduzir uma superioridade da empresa privada em termos de produtividade medida segundo esse critério.

Outros fatores também interferem no IPK, notadamente os que se referem ao tipo de atendimento urbano realizado em diferentes tipos de cidades. Pode-se então diferenciá-los, por exemplo, conforme o transporte efetue-se nas megalópoles (São Paulo e Rio de Janeiro), nas metrópoles regionais acima de um milhão de habitantes, nas periferias desses dois tipos de cidades, nas capitais (da ordem de meio milhão de habitantes) ou nas cidades médias do interior.

Verifica-se uma variação da produtividade operacional inversa ao tamanho das cidades: quanto maior a importância das cidades, mais baixo é o IPK médio. Claramente, o IPK parece depender menos do tamanho das empresas que do das cidades: sua extensão, as condições da circulação urbana, bem como a organização das redes e a agregação da demanda determinam o rendimento operacional das empresas. Da mesma forma, observa-se uma variação do tamanho médio dessas de acordo com o tipo de cidade: quanto maior a importância da aglomeração, maiores são as suas empresas de ônibus e menor a sua produtividade em IPK. $O$ que poderia parecer uma evidência remete às condições de rendimentos de escala, que não são independentes das estruturas espaciais nas quais o serviço de transporte está organizado. Observa-se, além disso, que, na mesma categoria das metrópoles, as variações do IPK são mínimas: 2,55 em média para as empresas com mais de cem ônibus, e 2,59 para as outras. Dessa forma, existe no tamanho das cidades e na organização dos mercados, uma variável explicativa intermediária entre o tamanho das empresas e a sua produtividade operacional.

Tal assertiva faz retornar a uma análise em termos de mercados. Pode-se deduzir da Tabela 9 que o mercado das megalópoles incita à concentração em grandes empresas, da ordem de um valor médio de 230 ônibus por

\section{TABELA 8}

\begin{tabular}{|c|c|}
\hline \multicolumn{2}{|c|}{ IPK municipal por setor } \\
\hline Setor & IPK Médio \\
\hline Privado & $\mathbf{3 , 0 1}$ \\
\hline Público & 2,88 \\
\hline Total & 2,98 \\
\hline
\end{tabular}

Fonte: OnibuCad 
TABELA 9

\begin{tabular}{|c|c|c|}
\hline \multicolumn{3}{|c|}{$\begin{array}{c}\text { Produtlvidade por categoria } \\
\text { de núcieo urbano }\end{array}$} \\
\hline Cldades & IPK Médio & Frota Média \\
\hline Megalópoles & 2,57 & 230 \\
\hline Metrópoles & 2,99 & 91 \\
\hline Periferias & 3,19 & 105 \\
\hline Capitais & 3,49 & 65 \\
\hline Cidades médias & 3,04 & 67 \\
\hline Total & 2,98 & 119 \\
\hline
\end{tabular}

Fonte: OnibuCad

companhia, e que essas operam em condições que não são as mais favoráveis à produtividade operacional (a qual não tem incidência direta sobre a rentabilidade comercial, que depende das tarifas praticadas, mais elevadas nas metrópoles que nas outras cidades). Os mercados das metrópoles e periferias são explorados por empresas com tamanho médio significativamente menor (em torno de uma centena de ônibus), porém com produtividade maior, sobretudo no atendimento às periferias urbanas onde se efetuam importantes fluxos migratórios pendulares de caráter metropolitano. Enfim, os mercados das capitais e cidades médias são explorados por empresas ainda menores (média de 65 veículos). A produtividade média é a mais elevada entre todos os sistemas analisados.

A diminuição dos mercados urbanos intervém na maior parte dos indicadores de produtividade aqui analisados. Com efeito, se a quantidade de efetivos é função direta do tamanho das empresas, medido segundo suas frotas de ônibus, a produtividade será superior nas pequenas cidades e inferior nas metrópoles. A concentração das empresas depende dos mercados nos quais elas se posicionam e isso incide sobre as condições e sobre os custos de produção do serviço de transporte urbano. As práticas regulamentares, por seu turno, não serão estranhas a essa relação visto que, nas maiores aglomerações, o poder público impõe um tamanho mínimo às empresas. Ocorre, então, um duplo efeito do mercado e do poder público, que influem no sentido da concentração e da modernização das empresas, mas também de forma inversa sobre a sua produtividade. Desse modo, a noção de mercados diferenciados põe em questão a visão clássica de economia de escala, não se podendo mais preconceber "todos os outros fatores permanecendo constantes".

\section{CRESCIMENTO E CONCENTRAÇÃO DAS EMPRESAS}

Ainda que os indicadores de produtividade não permitam destacar os fatores de escala que fariam aumentar as dimensões das empresas de ônibus, observa-se uma tendência histórica ao seu crescimento. No Brasil dos anos cinqüenta, predominavam as pequenas empresas de caráter familiar ou artesanal: hoje, as grandes empresas privadas. Existem muitas razões para isso, que vão desde a conquista de mercados em plena expansão e as práticas monopolistas de poderosos proprietários sobre o mercado, até outras de caráter institucional. A regulamentação em vigor nas últimas décadas, de fato, tem favorecido a concentração das empresas visando a modernizá-las e a organizá-las em redes.

Face à impossibilidade de apresentar em detalhe essa evolução, observam-se apenas as suas manifestações na amostra utilizada, as quais nos permitem reconstituir a evolução das frotas das empresas estudadas desde os anos sessenta (figuras 5 e 6 ). Se a metade dessas empresas tinha então menos de vinte ônibus, somente $11 \%$ permaneceram nessa categoria, com a sua frota tendo caído de $9 \%$ do total para apenas $1 \%$, hoje. Algumas dessas empresas entraram na categoria de médias (de 20 a 75 ônibus), cuja importância relativa passou de 33\% em 1965 a 39\% em 1992. Outras tornaram-se grandes (até 200 ônibus) tendo essa categoria passado de $17 \%$ a $32 \%$ da amostra. Enfim, empresas acima de 200 onibus só existiram a partir de 1970, mas representam um quinto da amostra e reúnem mais da metade da frota total (tabela 1 e figura 1). Na Figura 5, vê-se uma curva muito acentuada, representando as pequenas empresas que, em trinta anos, tornaram-se não só médias mas, sobretudo, empresas grandes e muito grandes. A evolução é bem mais contrastada no que se refere às participações relativas da frota total dessas empresas (figura 6), cujo crescimento favorece, essencialmente, as maiores empresas, em prejuízo das outras categorias. Fala-se, assim, da transformação de transportadores em empresários, depois em proprietários de ônibus, o que implica importantes mudanças de comportamento profissional. Seria ainda necessário acrescentar a concentração das próprias empresas, com a cons- 
FIGURA 5 Evolução do tamanho das
empresas 1960-1992

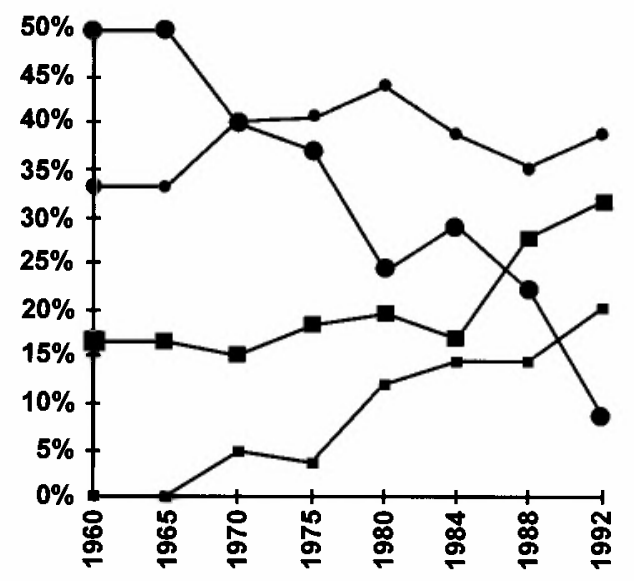

FIGURA 6

\section{Evolução da frota das empresas 1960-1992}

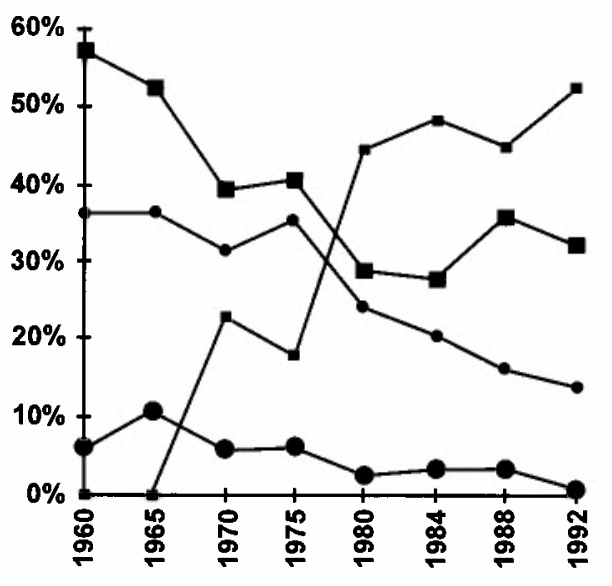

Fonte: OnibuCad

tituição de grupos empresariais presentes em diversas cidades.

Nas três últimas décadas, sobrevieram condições particularmente propícias ao crescimento vertiginoso das empresas, com a urbanização maciça, a explosão das necessidades de transporte, a expansão dos mercados urbanos, o desenvolvimento da indústria nacional de ônibus e as políticas racionalizadas aplicadas pelos poderes públicos. Na figura 7 observam-se patamares: quarenta ônibus em média nos anos sessenta, com um máximo de 140 ônibus por empresa ; um aumento vigoroso entre 1975 e 1984, ano em que se atingem, em média, 85 ônibus por empresa e um tamanho máximo de 478 ônibus; e enfim um salto em 1992, onde se passa a 120 ônibus em média por empresa, com três delas atingindo os 700 ônibus.

É difícil imaginar que esse crescimento do tamanho das empresas não esteja ligado a uma prática comercial que se acentua à medida que aumentam as escalas de operação. Não se deve esquecer, com efeito, que as empresas privadas de transportes raramente se beneficiam com subsídios diretos da parte dos poderes públicos, mesmo se esses incentivam indiretamente seus investimentos em material rodante e instalações fixas. $\mathrm{O}$ crescimento das empresas, então, é também a concentração do setor em torno de um número restrito de sociedades, como aparece claramente nas figuras 5 e 6. Quaisquer que sejam as vantagens (notadamente do serviço prestado, em comparação com outras cidades latino-americanas) e os inconvenientes (controle dos mercados por oligopólios), o processo de concentração é uma evolução marcante do transporte brasileiro. O processo parece estar estendendo-se aos países vizinhos, como a Argentina, onde as tradicionais sociedades cooperativas cedem lugar a oligopólios ligados aos mercados de serviços urbanos; podese surpreendê-lo, também, no México, onde se procura remediar a proliferação dos microônibus.

\section{FROTA ÓTIMA?}

Existiria uma escala de operação ótima das empresas de ônibus urbanos, resultando de uma forma pertinente de organização do serviço de transporte nas cidades dos países em desenvolvimento? No quadro da análise das economias de escala, poder-se-ia responder positivamente a essa pergunta para, mesmo na ausência de função de custos, apoiar a argumentação a favor das pequenas entidades. 
Mas as comparações entre cidades e países, entre empresas ou entre linhas de uma mesma rede, obrigam a que se saia do estrito quadro da economia marginalista.

Mesmo numa situação tão homogênea quanto a brasileira - parametrizada por uma legislação trabalhista que contingencia os salários (e todas as empresas da nossa amostra são sindicalizadas), por planilhas lho guarda uma notória importância.

Haveria um tamanho ótimo? Ou não existiriam, antes, diversas escalas de operação pertinentes, em função dos tipos de aglomeração e dos serviços prestados, escalas essas marcadas por limitações de diversas naturezas? Limitações físicas primeiramente, na medida em que a alocação em uma ou mais garagens, oficinas e equipamentos de manu-

FIGURA 7

\section{Frota média e frota máxima das empresas}
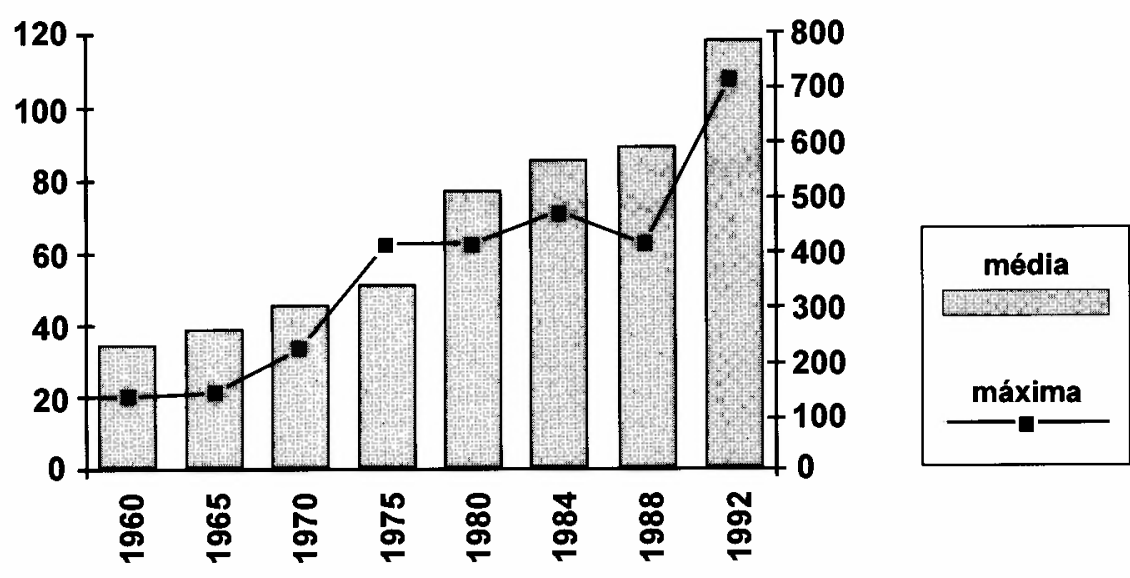

Fonte: OnibuCad

de custos municipais (inspiradas na planilha do Geipot), por uma política nacional de apoio ao investimento (Finame/Bndes) e por uma oferta oligopolista de ônibus (sob a égide da Mercedes-Benz) - nota-se como são diferentes os comportamentos das pequenas, médias e grandes empresas em relação a esses fatores. E, em termos de produção, os desempenhos referentes aos tamanhos de empresas são bastante atípicos, quer se pense em termos de capacidade oferecida ou de serviços prestados. A noção de veículo/quilômetro aplicase às maiores empresas, em que o investimento em ônibus domina a lógica da produção. $\mathrm{E}$ a de veículo/passsageiro está mais próxima das pequenas empresas, em que o fator traba- tenção dos veículos condiciona tanto a operação quanto a qualidade do serviço. Limitações técnicas em seguida, ligadas ao maior ou menor grau de controle da estrutura de produção. As limitações sociais são ditadas pelos efeitos de tamanho sobre a política de gerenciamento do pessoal. Contudo, existem também limitações externas, tais como a configuração e o tamanho das cidades ou a estruturação dos atendimentos à demanda. $\mathrm{E}$ esses diferentes tipos de limitações parecem flutuar em função da dinâmica dos mercados e das estruturas urbanas: assim explicar-seia a tendência à concentração das empresas e a dinâmica de constante renascimento de unidades de produção de tamanho inferior.

$O$ autor agradece a todos os membros da equipe que fizeram apartes substanciais e valiosos no desenvolvimento do projeto dessa pesquisa. Entre eles, quatro estiveram diretamente envolvidos no trabalho de dados utilizados nesse artigo: Lúcia Sequerra(EAESP/FGV) para Onibulis, Silvana Zioni (SP Trans - USP) para ÔnibuCad; Paulo Itacarambi (Oficina Consult.) pela metodologia e Anísio Brasileiro (UFpe/ Eng. Civil) para o processamento.

Especialmente grato às instituições: EAESP/FGV, que possibilitou o convênio entre CNPQ (área de cooperação internacional) e a Orstom (Instituto francês de pesquisa científica para o desenvolvimento em cooperação). 